\title{
Recent advances in simulation of power electronics converter systems
}

\author{
MANJUSHA DAWANDE*, VICTOR DONESCU, ZIWEN YAO and \\ V RAJAGOPALAN
}

CPEE-Hydro-Québec/NSERC Industrial Research Chair, Département de génie électrique, Université du Québec à Trois-Rivières, C.P.500, Trois-Rivières, Québec, G9A 5H7, Canada

* Present address: Department of Electrical Engineering, University of Roorkee, Roorkee 247667 , India

e-mail: kmsee@ rurkiu.ernet.in; rajagopalan@uqtr.uquebec.ca

\begin{abstract}
This paper presents a comprehensive state-of-the-art of the recent advances in simulation of power electronic converter systems. Knowing the importance of simulation, this paper reviews the various methods of modelling, circuit analysis approaches, numerical techniques etc. Several general purpose simulators and dedicated power electronic simulators have been discussed. A few demonstrative examples of simulation of power electronic converters by using different simulators are provided. Practical difficulties in simulation, challenges, new developments and scope for future work are also discussed.
\end{abstract}

Keywords. Power electronic converter; power electronic simulator.

\section{Introduction}

Power electronics has gone through intense technological evolution during the last three decades. Power electronic converter systems have captured a major place in it, as they find wide applications in industry. It has been reported in the recent IEEE PELS (Newsletter 1997) that 'Analysis and control of power converters' is the area of highest interest $(65 \%)$ in power electronics. At present, in research, design and development power electronic converter systems, modelling and simulation are widely used and became indispensable before practical hardware implementation.

Design of power electronic converters requires fairly sophisticated analysis, simulation tools and detailed design procedures involving tolerance analysis and worst-case design before building the actual system. The computation of steady state solution is an essential first step in most of the design studies (Rajagopalan 1987). Computer-based design automation tools are expected to have an increasing influence on improving the reliability of power electronic systems (Kang \& Lavers 1994). Accurate, fast and cheaper simulation 


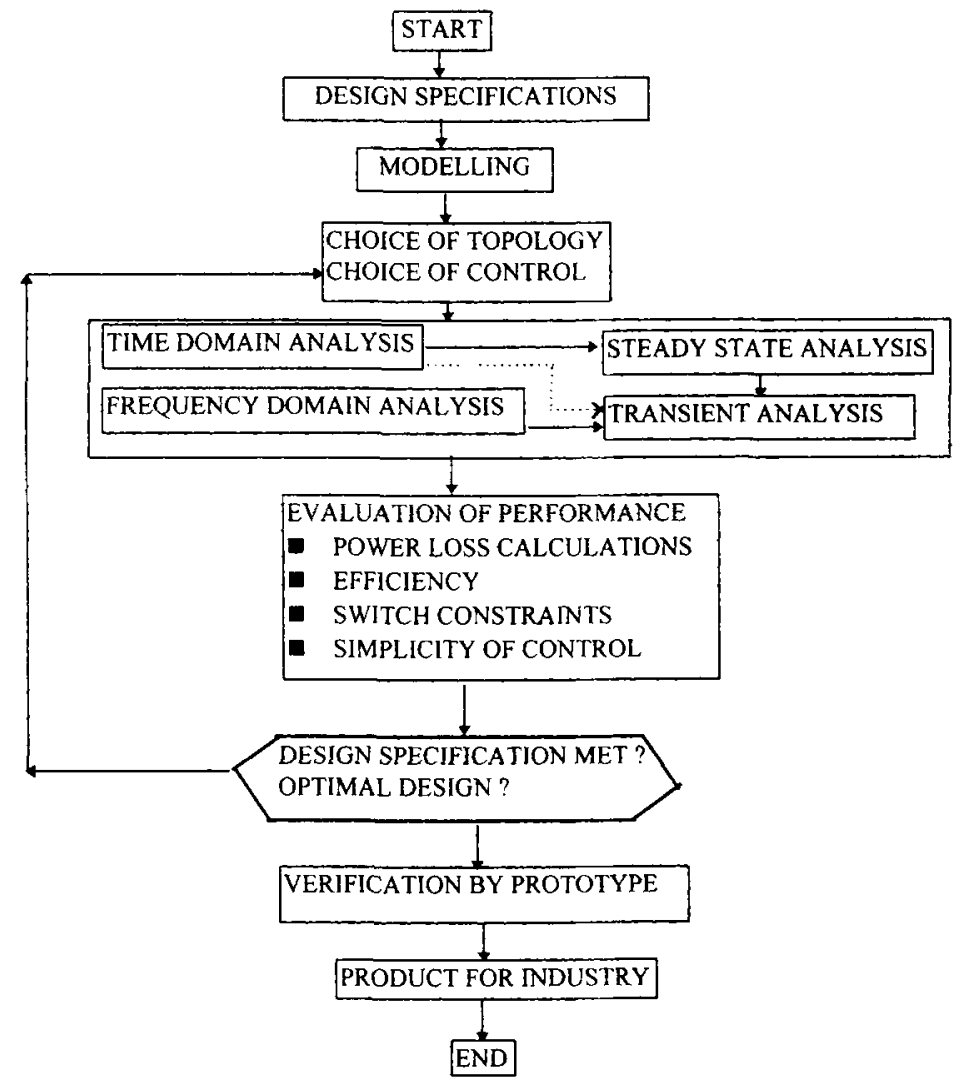

Figure 1. Flow chart for design process.

methods are required for (1) comprehensive system performance, (2) efficient designs, (3) discovering possible problems due to abnormal operating modes, (4) optimal design, (5) sensitive study based on the various parameters, (6) knowing the behavior of circuit at various levels, (7) predicting the interaction with other networks, and (8) avoiding destructive laboratory tests etc. Therefore, the normal design process should follow the algorithm given in figure 1. It is always advisable to study the system thoroughly, to determine the influence of all the parameters, to raise the maximum doubts for its worst-case operation and get the solutions through simulation, before finalizing the optimal design of power electronic converters. Micro-modelling and macro-modelling of power semiconductor devices, new simulation tools and user-friendly environments are currently available for the simulation of power electronic converters (Rajagopalan et al 1990, 1992, 1995; Rajagopalan 1995).

This paper gives a comprehensive state-of-art of the several simulation techniques employed to the power converters. It describes the micro- and macro-modelling of power components, time and frequency domain analysis, different circuit analysis approaches, various numerical techniques used in simulation etc. Several general purpose simulators such as MATLAB-SIMULINK, SIMNON, EMTP, EMTDC, PSPICE, SABER etc. are reviewed. Several dedicated power electronic circuit simulators such as ATOSEC5, PSIM, SIMUPELS are briefly discussed. Computer-aided learning tools like CATPELS are also 
mentioned. Some examples are demonstrated in different simulators. The paper discusses some of the practical difficulties in the simulation process and explores the challenges that are to be overcome to make simulation more efficient and attractive to design engineers. Finally, the future trend of systematic controller design, i.e. hardware implementation directly from digital simulation, is introduced.

\section{Simulation techniques}

The importance of simulation is wisely referred to as 'Question of questions' (Kassakian 1981) and many simulators have evolved after realizing its importance. General purpose simulators such as MATLAB-SIMULINK, SIMNON etc. are widely used in various engineering disciplines while PSPICE, SABER etc. are used especially in electrical circuit analysis. Simulators like EMTDC, EMTP are mostly used in power system area and a few circuit simulators such as ATOSEC, PSIM, SPICE, SIMUPELS, KREAN are dedicated to power electronic converter systems.

\subsection{Micro- and macro-modelling}

All currently available power electronic simulators using either software packages such as EMTP, PSPICE, SIMNON and MATLAB-SIMULINK or dedicated power electronic simulators such as ATOSEC5, and PSIM use a macro-modelling approach for modelling power semiconductor elements. The micro-model used for the semiconductor switch can be any one of the following classes.

(i) Ideal;

(ii) two-valued resistor;

(iii) two-valued inductor;

(iv) subcircuits;

(v) equations describing switch.

The ideal model gives a simple idea of short circuit when the switch is 'on' and open circuit when the switch is 'off' (Lai 1994). Two-valued resistor (Kang \& Lavers 1994) and two-valued inductor (Rajagopalan 1988) models implement the low impedance in the 'on'-state and high impedance in the 'off'-state. A number of sources, resistors, and capacitors make the switch model with subcircuits, while the nonlinear equation, representing the switch is used in the equation switch model. This modelling approach has been used and validated by several researchers for the analysis of large power electronic converters. It is useful to develop a library of models for the various components of the power electronic system, namely, power semiconductor devices, electrical machines, power electronic converters and power electronic control strategies. Such a library of models must be available in a user-friendly environment which can be advantageously used for building power electronic converter circuits and systems for analysis. These user-friendly models are now available for various simulators such as SABER, PSIM and SIMUPELS etc. 


\subsection{Time/frequency domain}

Simulation techniques can be based on the time domain or the frequency domain principle. To study the switching operation effect on power converters or high switching frequency operated converters time domain analysis is usually used (Liu et al 1993; Tymerski 1993). Analysis, design, steady state or transient state conditions of the controller or power electronic converter are usually studied by frequency domain based simulation techniques (Maranesi 1992). It is not always easy to derive models for frequency domain based analysis for complex power converter topologies.

\subsection{Circuit analysis approach}

Simulation techniques are based on any one or two of the following circuit analysis approaches.

2.3a Circuit modelling techniques: (i) State variable approach (SVA); (ii) nodal analysis (NA); (iii) modified nodal analysis (MNA); (iv) state-space averaging technique (SAT).

The SVA has been widely used in the power electronics area. This approach formulates a set of circuit equations in terms of branch voltages and currents and they are called state equations. These state equations can be further solved by any numerical method. SVA approach has been used by dedicated power electronic simulators such as ATOSEC5 (Rajagopalan \& Sankara Rao 1975), SCRIPT (Oms et al 1989), COSMIR (Hsiao et al 1989), CAP (Liu et al 1993).

The traditional nodal analysis based approach is used in EMTP in the area of power systems. Nodal analysis based power electronics simulator is also reported as PECAN (Lavers et al 1990). However nodal analysis-based simulators are not so efficient as they are incapable of handling current depending elements, performing fast steady state analysis, and it is difficult to obtain the branch currents in many power electronic circuits. These difficulties are overcome to some extent in Modified Nodal Analysis (MNA) as it includes circuit components such as voltage sources and other current depending elements. This approach has been used in many simulators such as PSPICE, SABER, KREAN etc. MNA has been implemented for switch modelling also (Sudha et al 1993).

State-space Averaging Technique (SAT) is mainly based on state averaging concept. This technique converts a nonlinear, time varying, switched circuit into a equivalent circuit by averaging state variables. It is widely used for the analysis of switched mode converters (Middlebrook 1989). Direct implementation of SAT is usually done in SPICE simulator. Recently, computer-aided modelling technique of $d c-d c$ converters, using SAT, is also proposed (Chapman \& Cichards 1992).

2.3b Symbolic math analysis (SMA): In Symbolic Math Analysis, the most common modes of operation of a converter topology are identified together with the corresponding equations for the mode changes. The analysis consists in solving the system equations from an initial operating mode with arbitrarily chosen or known initial conditions through a pre-determined sequence of the different operating modes for a whole cycle of operation. 
The analytical solutions for each mode of operation is derived for each mode in terms of the unknown initial conditions. Each mode of the system is governed by a set of total differential equations. Generally, the conditions for mode changes are governed by nonlinear equations. Therefore, the solution for a complete cycle requires the computation of all the initial conditions through an iterative procedure. With the availability of general purpose software such as MATLAB and its toolbox called Symbolic Math Analysis or others such as.Mathematica, Mapel etc., it is now possible to use the sequential method of analysis for the generation of design curves for new circuit topologies (Rajagopalan 1995). This approach has been used to develop the switch power converter simulator named SPANTRAN (Liberatore et al 1991).

There are a few other analytical methods which are used for power electronic converter simulation. Sample-data modelling techniques have been specifically used for the study of $d c-d c$ converters which permit derivation of suitable transfer functions of the system thereby permitting traditional control system design methods to be used for the tuning of control parameters (Verghese et al 1986).

\subsection{Numerical methods}

Various numerical integration methods have been used in power electronic simulators. Traditional methods such as Newton-Raphson, Runge-Kutta, Backward Differential Formula (BDF), Backward Euler, Trapezoidal, Implicit higher order BDF named Gear etc., are implemented in simulators (Mohan et al 1994).

\section{Simulators}

Many simulators are now available for the simulation of power converters. In the following section, some of the simulators with which authors are familiar are described.

\subsection{General purpose simulators}

3.1a MATLAB-SIMULINK: MATrix LABoratory (MATLAB) is a high performance iterative package for scientific engineering numerical computation (Matlab 1992). MATLAB integrates numerical analysis, matrix computation, signal processing and graphics in an user-friendly environment. SIMUlation LINK (SIMULINK) within the MATLAB works in two phases, (1) model definition (2) model analysis (Simulink 1992). It constructs simulation by building blocks or modules. SIMULINK has graphical interfaces for building blocks. It uses the simplified switch models for power electronic converters. It uses the state equation models to solve any continuous/discontinuous, linear/nonlinear system. This simulator has a great facility to exchange the data between MATLAB and SIMULINK. It generates the graphical output using built-in functions. Simulink simulation slows down for the large power electronic converter systems because of its constant passing of data to and fro from MATLAB. The user-friendly graphical capability of MATLAB and various controller design functions are of great advantage in this simulation environment. 
3.1b SIMNON: This simulator provides the time domain responses. It requires a separate tool for dealing with frequency domain analysis. It constructs simulation by building blocks or modules. It uses the state equation models to solve any continuous/discontinuous, linear/nonlinear system. It generates the graphical output using built in functions. The simplified switch models are used in power electronic converter's simulation. SEMAS is an example of a software that has been built in SIMNON environment for the time domain analysis of power electronic systems (Ba-Razzouk et al 1993). New SIMNON for windows further provides user-friendly interfaces (Simnon et al 1993).

3.1c EMTP: Electro Magnetic Transients in Power system (EMTP) is widely used in large scale power systems (Meyer \& Liu et al 1974). This simulator has models of transformer, transmission lines, machines and switch models such as diodes, thyristors etc. The nodal approach is used for solving the circuit equations. Here, trapezoidal or factorization methods are used for solving these equations and the time step for integration is specified by the user.

3.1d EMTDC: EMTDC is basically a circuit analysis program (EMTDC 1986). It can be used to model any dynamic systems that can be constructed from building blocks consisting of integrators, limits, logic functions, delays etc. known as Continuous System Modelling Functions (CSMF). Furthermore, electric circuits and CSMF can be interfaced to create a model of both the circuit and controls. EMTDC can be used as a time domain simulation program for electric power and control systems. It also supplies methods for frequency scanning. Usually it is used for studying dynamics of power systems with various converters such as HVDC, STATCOM etc.

3.1e SPICE: Simulation Program with Integrated Circuit Emphasis (SPICE) is used widely in electronic circuit analysis (Nagel 1975). It offers the various models, subcircuit libraries, graphical pre-processors and post-processors etc. Both time-domain and frequency-domain analysis are possible in SPICE. The circuit equations are developed by nodal approach and Gaussian elimination technique is used for solving these equations. Voltage dependent switches are modelled by nonlinear resistors. Nonlinearities can be resolved within the program. However the choice of Trapezoidal or Gear methods is also possible. Here, the time steps are automatically adjusted within the programs. SPICE is used in power electronics for simulation at low power levels e.g. Switch Mode Supplies. SPICE is available in Personal Computer environment, known as PSPICE. It is very popular for circuit analysis because of its availability at very reasonable cost for classroom environments.

3.If SABER: This simulator is well suited for nonlinear analog and digital circuits, especially for mixed mode circuits in power electronics (Xu 1990). It offers device models, machine models, models for mechanical parts such as gears, dampers, fans etc. This simulator allows the developing of new models in dedicated description language MAST (Franz et al 1990). Designers can use other languages such as, FORTRAN, C, Pascal etc. 
for developing the new models. This additional facility of external modelling makes the SABER more useful in power electronics.

\subsection{Dedicated power electronic simulators}

3.2a ATOSEC5: Analyse Topolologique des Systemes Electroniques en Commutation (ATOSEC5, French acronym) is power electronics dedicated simulator (Rajagopalan \& Sankara Rao 1975). The power electronics system is described in the form of a set of state equations. These state equations are solved by Backward Euler method. In order to ensure the numerical stability the Newton Raphson iterative method is used for the solution. A constant time step is chosen for the solution of state equations. Several subroutines are used for FIRING, BLOCK, EXTFIR for well defining the power electronic systems. This offers a library of semiconductor switches such as diode, transistor, FET, GTO, MOSFET and special purpose switches such as PWM, hysteresis etc. User can define special kind of switch which is not covered in ATOSEC through EXTFIR and it can be used in principle subroutine for the solution. ATSECG interface module can be used to prepare the schematic diagram of the circuit. The circuit element values can be shown in a specific manner and can be used in a data file which can be obtained from ATOSECG interface module. ATOPLOT interface module shows the simulated curves which can be visualized during simulation. Any power electronic system, e.g. circuit with 100 branches, 60 nodes and any 40 semiconductor switches, can be easily handled by ATOSEC. All the programs are written in FORTRAN 77.

3.2b PSIM: Power electronic circuit SIMulator (PSIM) is a dedicated power electronic simulator (Jin 1995, 1996). It uses the nodal and trapezoidal approaches for circuit equations. It contains the library of several switches such as diodes, thyristors, transistors and bi-directional switches. It also contains the commonly used circuits such as three phase transformers, thyristor converters, PWM voltage/current source inverters. Apart from using the actual control circuit, transfer function blocks and other function blocks can also be used in PSIM. All programs are written in FORTRAN. The first step is to create or edit the power electronic circuit in OrCAD or SIMCAD and then the circuit is simulated in PSIM and results can be viewed in SIMVIEW. Both SIMCAD and SIMVIEW are written in Microsoft Visual $\mathrm{C}^{++}$.

3.2c SIMUPELS: SIMUlation of Power Electronic Systems (SIMUPELS) is a userfriendly simulator built in popular MATLAB-SIMULINK environment (Ba-Razzouk et al 1995). Power semiconductor devices are modelled using SIMULINK. It also explains how to use the generated device models to construct any power electronic converter. Nodal approach and mesh type formulation of circuit equations are used. Extensive libraries of converters, control circuits, and electrical machine models are included in the simulator. The simulator contains several examples of simulation of many power electronic systems; in particular a number of case studies dealing with $a c$ and $d c$ drives are available. All the simulations reported in SIMUPELS use the GEAR algorithm. 
3.2d KREAN: This simulator is dedicated to power electronics especially for power converters with high switching operation (KREAN 1990; Nilssen \& Mo 1990). All switches are modelled as ideal switches. Nonlinear components are described in FORTRAN subroutine and linked to the main program. Nodal approach is used for developing circuit equations. Runga-Kutta, Newton-Raphson, and sparse matrix methods are used for solving these equations.

\subsection{Power electronic tutor (CATPELS)}

Computer-Aided Tutor in Power Electronic Systems (CATPELS) is a useful multimedia tool which helps the user to understand a simulation and a subject from basic to advanced level. This involves sophisticated computer-aided analysis and design tools. This tutor outlines the major requirements and concepts of a computer-aided learning aid for power electronic systems and gives the characteristics of a prototype of an expert system named CATPELS (Rajagopalan et al 1995). The open architecture of the run-time version of the CATPELS software provides not only the basic information for beginners and all the required tools for specialists but also permits a user (an instructor or a researcher) to expand its capabilities and to customize as per specific requirements.

\section{Demonstrative examples}

A commonly used example of three phase self commutated converter, shown in figure $2 \mathrm{a}$, has been analysed and simulated. Figure $2 \mathrm{~b}$ shows the simulated model in MATLABSIMULINK within SIMUPELS (Ba-Razzouk et al 1995) . Here, the power converter models are developed on the basis of switching function theory. The voltages at the converter input are synthesized from the $d c$ output as given in (1)-(3) below.

$$
\begin{aligned}
& e_{1}=\frac{\text { Vout }}{3}(2 . S 1-\mathrm{S} 3-\mathrm{S} 5), \\
& e_{2}=\frac{\text { Vout }}{3}(2 . \mathrm{S} 3-\mathrm{S} 1-\mathrm{S} 5), \\
& e_{3}=\frac{\text { Vout }}{3}(2 . \mathrm{S} 5-\mathrm{S} 1-\mathrm{S} 3) .
\end{aligned}
$$

The input current depends on the output currents,

$$
\text { iout }=i_{1} . \mathrm{S} 1+i_{2} . \mathrm{S} 3+i_{3} . \mathrm{S} 5
$$

The appropriate space-vector PWM algorithm for the converter is implemented with the MATLAB files. The other auxiliary components referring to the generation of the space vector polar coordinates, the command circuit avoiding the short-circuit and the clock generator have been grouped in the desired parameters of the PWM generator (pulse frequency, number of pulses and modulation index etc.) in a user-friendly manner. Together with the modules for power converters and PWM techniques some special modules are designed for $a c$ filters and loads allowing an easy adjustment of desired component values. 


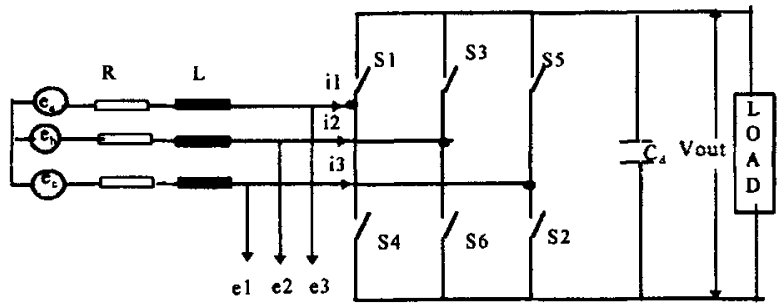

(a)

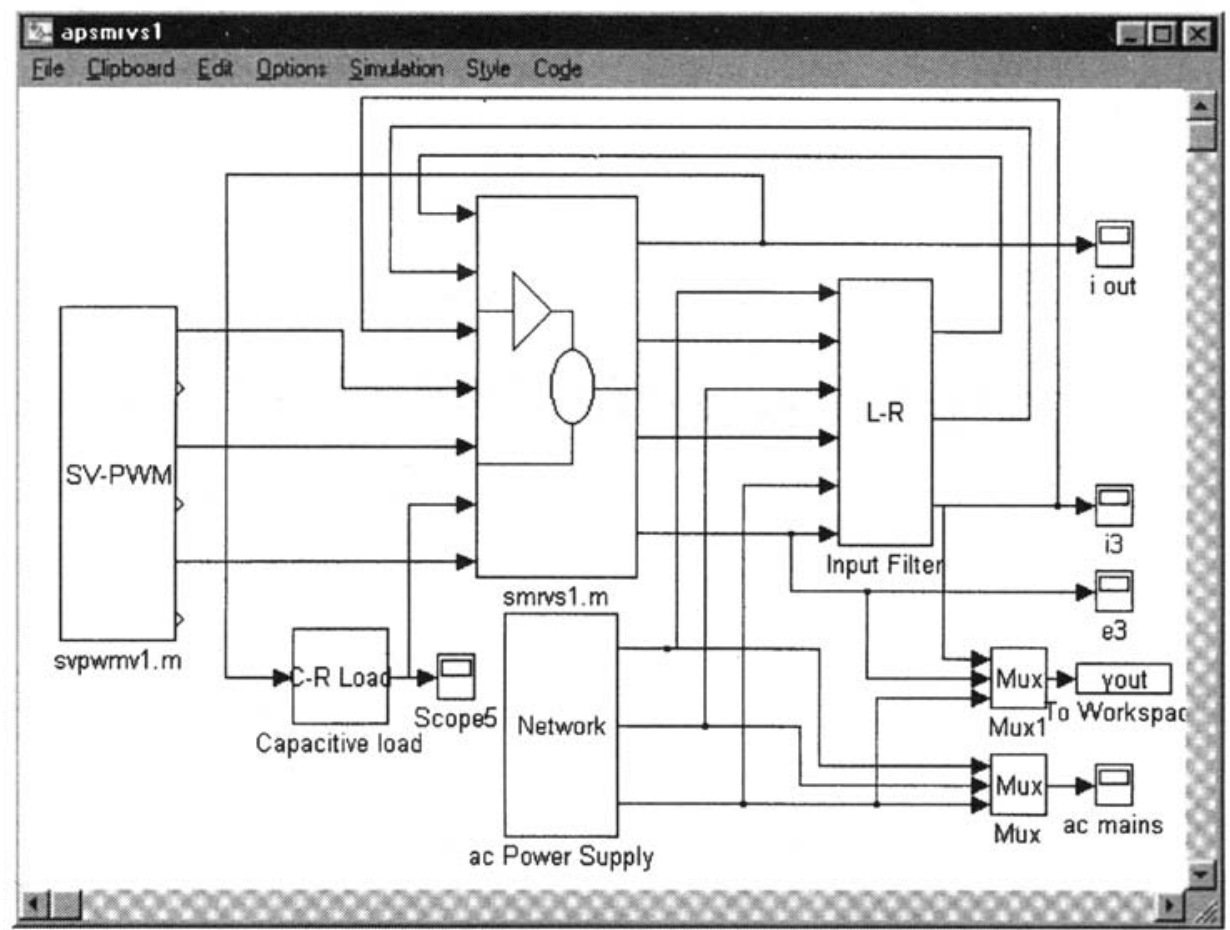

(b)

Figure 2. (a) Three phase voltage source converter. (b) Simulated in MATLAB-SIMULINK.

Three more demonstrative examples are provided in figures 3-5. Figure 3 shows the single-phase diode boost rectifier with single-switching device on $d c$ side in PSIM. Figures 4 and 5 show the three-phase boost rectifier with single-switching device on $d c$ side and simulated in MATLAB-SIMULINK and SABER respectively (Dawande \& Dubey 1996). Figure 6 shows a typical case study in CATPELS with various menu options available to the user for $a c-d c$ converters.

\section{Difficulties and challenges}

When the simulation of power electronic converters is carried out, a number of problems may occur due to imperfect models used for devices resulting in lower accuracy. To cite an example, when using macro-models for semiconductor power switches, it is not possi- 


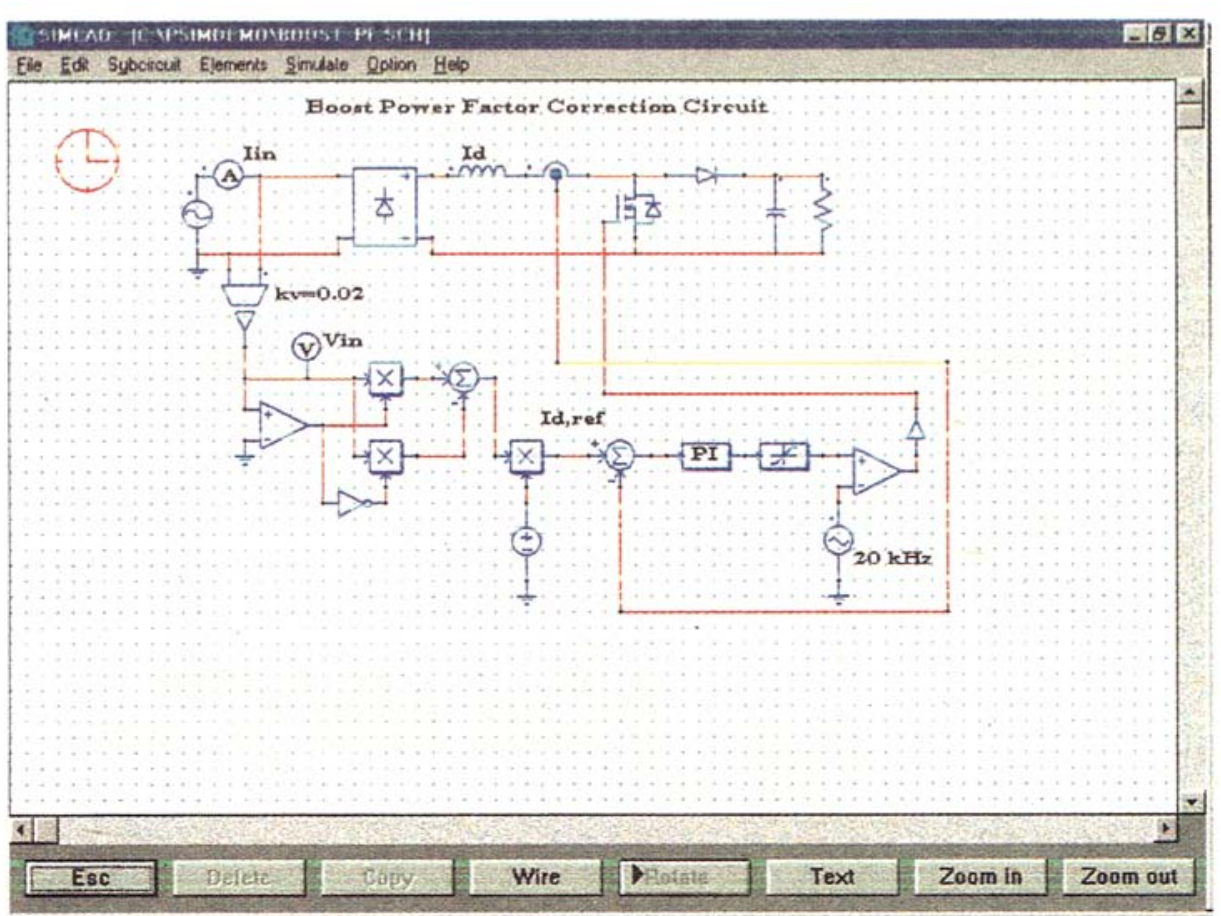

Figure 3. Single phase boost rectifier in PSIM.

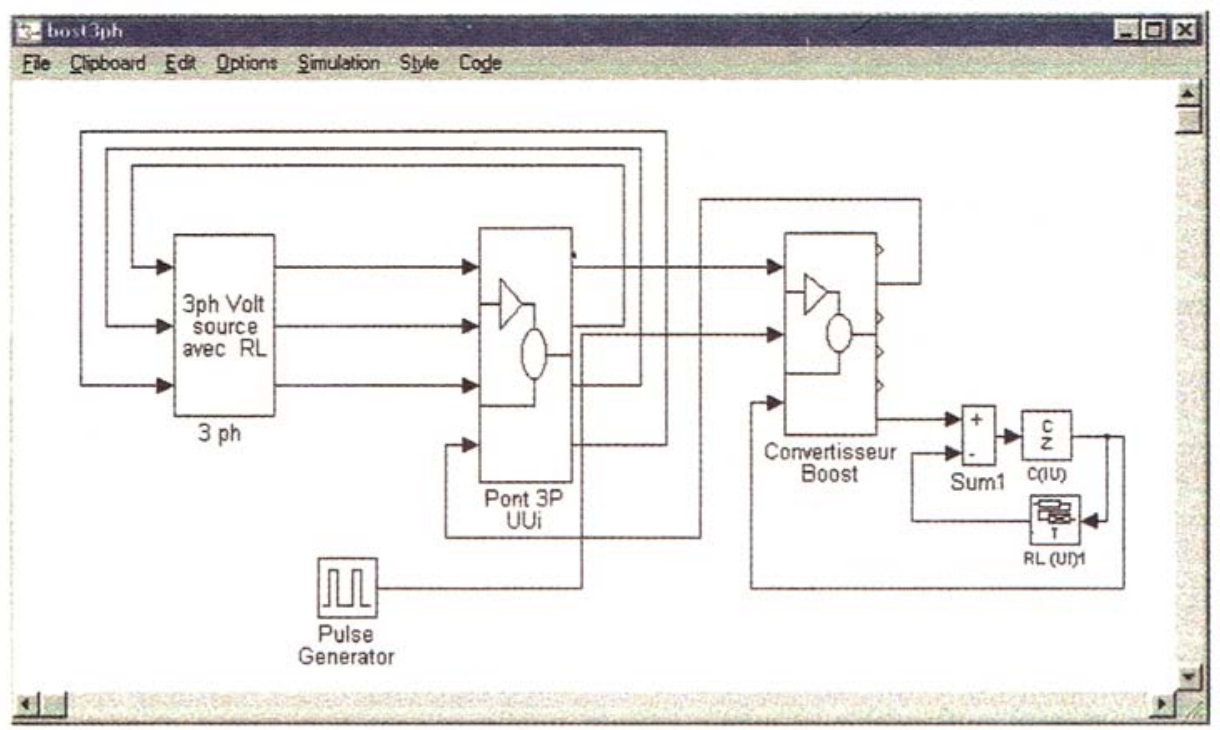

Figure 4. Three-phase boost rectifier in MATLAB-SIMULINK. 


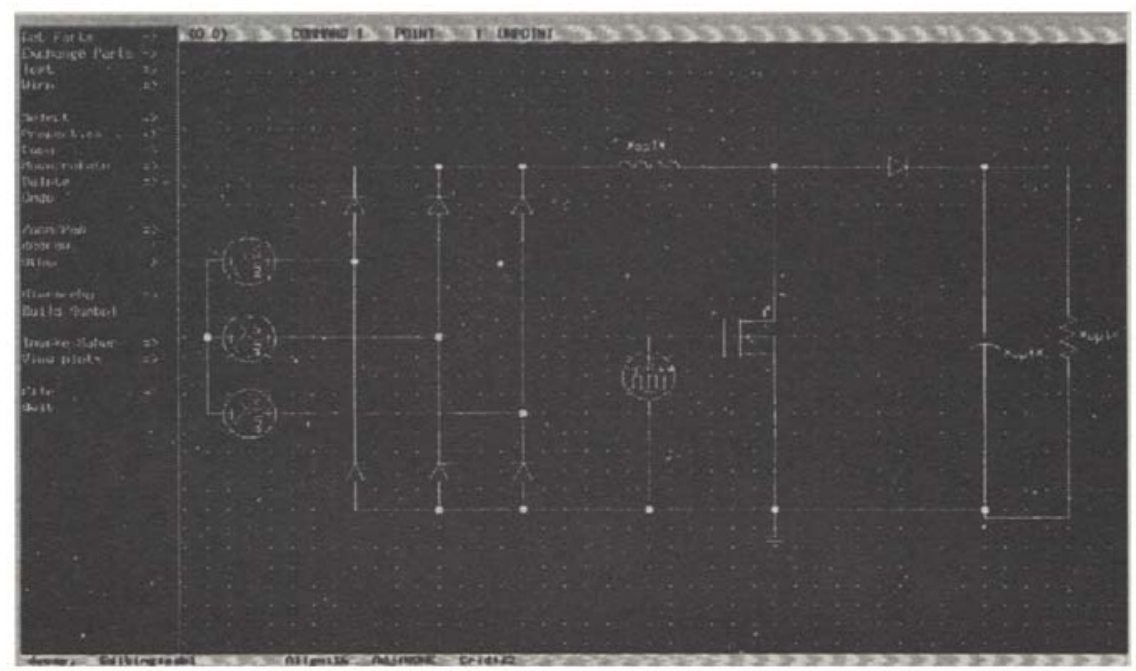

Figure 5. Three-phase boost rectifier in SABER.

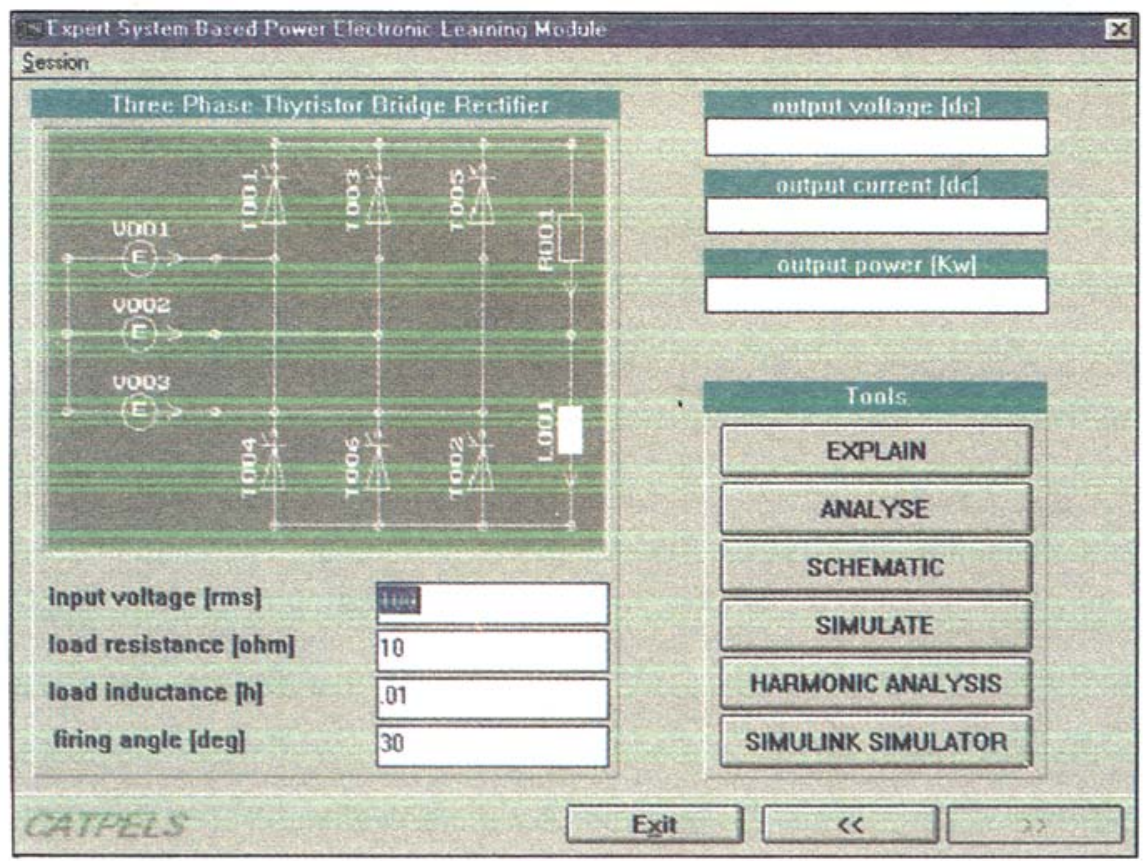

Figure 6. $a c-d c$ converter study in CATPELS. 
ble to calculate accurately the power losses in the devices during turn-on and turn-off of the devices. In order to calculate accurately these transitions, sophisticated physics-based semiconductor models (micro-models) are required for the switches. Use of such models for the study of power electronic converters increases the complexity, reduces the computational efficiency and even causes numerical unstability. Modelling of bipolar devices such as IGBT, GTO etc. are devoid of carrier diffusion property. Most of the switch models use a single variable equation and do not use the time-dependent partial differential equation for the proper characteristic of the device. Simulation in power electronics becomes difficult when there are sharp discontinuities in the circuits. The study of converter-fed machine requires extensive time for data preparation and solution.

The availability of various simulators dedicated to specific domains have some advantages and disadvantages when chosen for a given application. A universal simulator with a facility to link all the simulators in a user-friendly environment will be welcome. This can provide the study of a particular condition of a power electronic converter system by using a simulator that is most suitable from a library or bank of standard simulators. For the sake of discussion, consider the analysis of a power electronic converter system. The expected standard bank contains several simulators $X_{1}, X_{2}, X_{3}, \ldots X_{n}$. Suppose $X_{1}$ deals with the modelling of devices, which can model the converter with thyristors, MOSEFTs, IGBTs etc., e.g. NIST simulator; $X_{2}$ deals with steady/transient state response in time and frequency domain e.g., SIMUPELS; $X_{3}$ deals with high voltage application software like EMTP/EMTDC etc. Then the study of any converter system at all levels of application could be easily possible, without any limitations of a certain simulator, in a user-friendly environment. It will be beneficial for all university researchers and industry designers to have such a universal tool readily available for the analysis of any power electronic converter system. However, this approach is feasible only if such simulators are available at reasonable cost with time-sharing possibility on the Internet.

\section{Future trends and developments}

In the next few years, computer-aided design of power electronic converters will be more needed to reduce the design and manufacturing cost. The system which can be designed to control, implement and test the high speed control algorithms of power electronic converters and which can bring the hardware in the loop simulations in real experiments will be essential for future applications.

Presently, the link of simulation and hardware has been brought out by using dSPACE system in our research group. This system consists of Digital Signal Processor (DSP TMS320C40), input/output boards, graphical tool TRACE etc. The following systematic process is adopted.

A simulated system of harmonic compensation of three-phase converter is developed in MATLAB-SIMULINK. The necessary controller is designed in SIMULINK and grouped in the block of 'compensator discrete' (Yao 1997). After achieving the satisfactory simulated results, the controller is modelled in dSPACE environment with necessary input/output channels which are shown in figure 7a. This has to be built from the selected hardware library of dSPACE. Channels 1-3 sense the three input currents of a three-phase converter, 
while channels 3-6 sense the input voltages of a three-phase converter, through ADC board (DS2003). The processed output signals of the controller are delivered to hardware through DAC board (DS2103). The dSPACE Real-Time Interface (RTI) contains all the interface software necessary to integrate the combined development of the MATLAB, SIMULINK and Real-Time Workshop. Code generation from SIMULINK block diagrams is fully automatic. Figure $7 \mathrm{~b}$ shows a real-time interface which integrates the simulation and hardware. Figure 7c shows a controller model which has been downloaded to DSP. All the necessary input/output signals along with the controller signals are seen through graphical tool called TRACE in dSPACE. The option menu of TRACE for various signals is seen in figure 7c. The implementation of the simulated controller, directly to hardware using dSPACE is successfully done. The actual experimental monitored signals are seen in figure $7 \mathrm{~d}$.

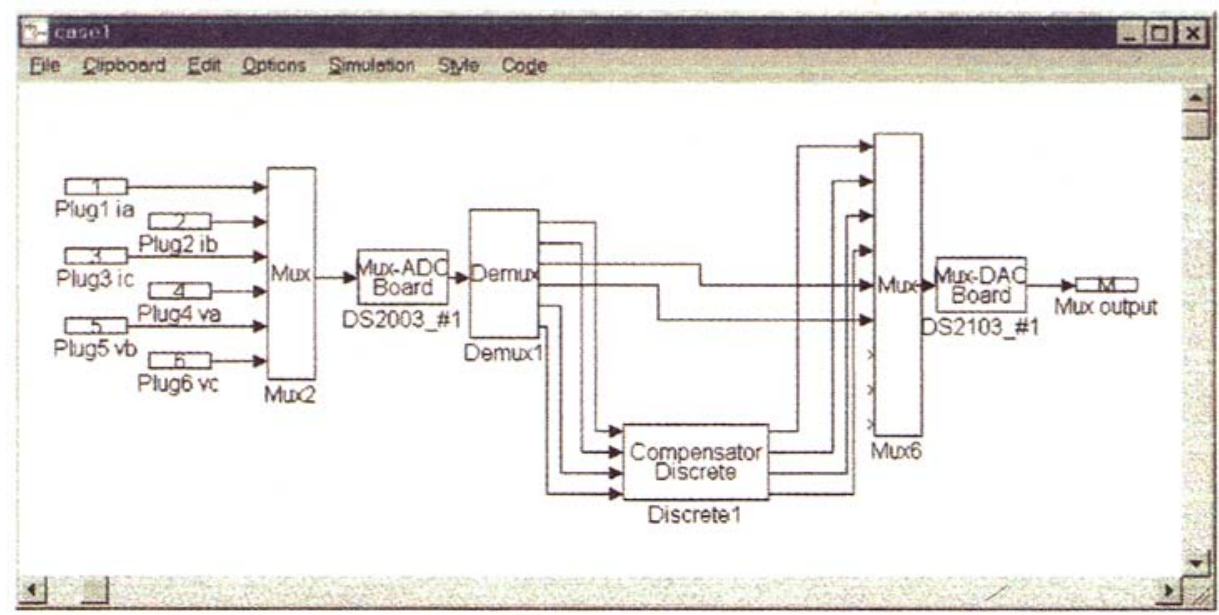

(a)
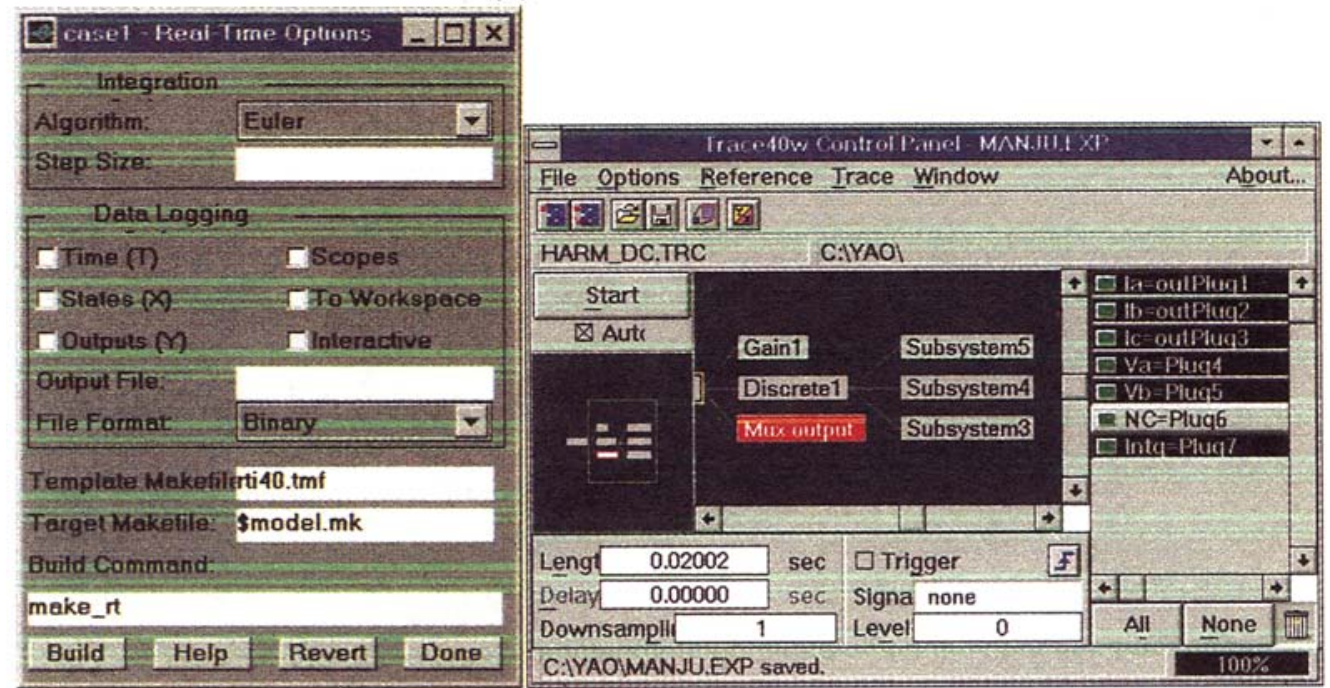

(b)

Figure 7. (Continued on next page.) 


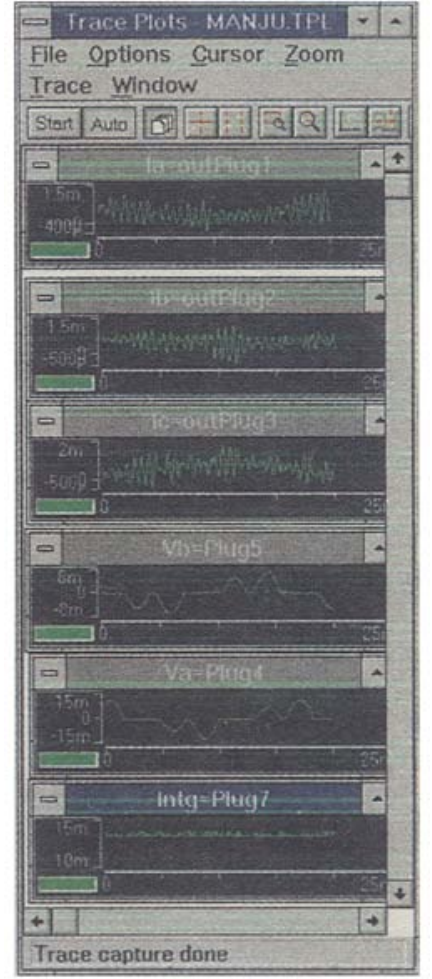

(d)

Figure 7. (a) Harmonic compensator model developed in dSPACE. (b) Real Time Interface integrating simulation and hardware. (c) Graphical TRACE tool showing simulated and experimental signals. (d) Monitored experimental results.

\section{Conclusions}

This paper gives a comprehensive state-of-the-art review of power electronic simulation techniques. It reviews various methods of modeling, circuit analysis approaches and numerical methods used in different simulation techniques. Several general purpose simulators such as MATLAB-SIMULINK, SIMNON, EMTP, EMTDC, SPICE, SABER etc. and dedicated power electronic circuit simulators like ATOSEC5, PSIM, SIMUPELS, KREAN are discussed in brief. Several demonstrative examples using different simulators are provided to show the importance and ease of simulation in power electronic converters. Considering the use of hardware in simulation which may be the essential future demand in power electronic converter systems, some new developments are introduced to show the wide scope of research and developments.

\section{References}

Ba-Razzouk A, Debebe K, Rafesthain T, Rajagopalan V 1993 SEMAS: A new simulation module for ac drive systems. Can. J. Electon. Comput. Eng. 18: 181-189

Ba-Razzouk A, Debebe K, Neacsu D O, Gheorghe M, Pittet A, Yao Z, Rajagopalan V 1995 SIMUPELS: Simulation of power electronic systems using MATLAB-SIMULINK software. Research Report, Chaire de Recherche Industrielle HQ-CRSNG, UQTR, Trois-Rivieres (Quebec), Canada 
Chapman M, Cichards R 1992 A method for improving the speed of simulation of switched mode power supply circuits. IEE Proc. Colloq. on CAD of Power Electronic Circuits, London

Dawande M, Dubey G K 1996 Programmable input power factor correction method for switch mode rectifiers. IEEE Trans. Power Electron. 11: 585-591

EMTDC 1986 Users' Manual. Manitoba HVDC Research Center, Canada

Franz G A, Ludwig G W, Steigerwald R L 1990 Modeling and simulation of distributed power systems. IEEE Power Electron. Syst. Conf. 90 pp 606-610

Hsiao C J, Ridley R B, Lee F C 1989 The simulation of switching converters using the new version COSMIR program. Proc. VPEC Seminar pp 121-130

Jin H 1995a PSIM: Power electronic system simulator. Software 1995, Department of Electrical and Computer Engineering, Concordia University, Montreal

Jin H 1995b Computer simulation of power electronic circuits and systems using PSIM. International Conf. on Power Electron. Seoul, pp 79-84

Jin H 1996 A new computer-aided design tool for switchmode power supplies. High-Frequency Power Conversion Conf. Las Vegas, Nevada, pp 117-122

Kang Y, Lavers J D 1994 Power electronics simulation: Current progress and future development. IEEE PELS 4th Workshop on Computers in Power Electronics pp 169-174

Kassakian J G 1981 Simulating power electronic systems - An overview. In Proc. US - Japan Cooperative Science Seminar on Analysis and Design in Power Electronics (Kobe, Japan) pp 45-54

KREAN 1990 The Norwegian Institute of Technology, Group of Power Electronic and Electrical Machines, N-7034 Trondheim, Norway

Lai J S 1994 Power electronics modeling and simulation. IEEE 4th Workshop on Computers in Power Electronics, Invited Paper, 0-7803-2091-3/94, pp 45-55

Lavers J D, Jin H, Cheung R W 1990 Analysis of power electronic circuits with feedback control: A general approach. Inst. Elec. Eng. Proc. B137: 4

Liberatore A, Manetti S, Piccirilli M C, Reatri A 1991 A new symbolic approach to the analysis of switch power converters. European Power Electronics Conf.-91 4: 489-490

Liu C C, Hsieh J, Chang G H K, Bocek J M, Hsiao Y T 1993 A fast decoupled method for time domain simulation of power converter. IEEE Trans. Power Electron. 1: 37-45

Maranesi P 1992 Small signal circuit modeling in the frequency domain by computer aided time domain simulation. IEEE Trans. Power Electron. 7: 83-88

Matlab 1992 MATLAB User Guide. The Math Works

Middlebrook R D 1989 Modeling current-programmed buck and boost regulators. IEEE Trans. Power Electron. 4: 36-52

Mohan N, Robbins W P, Undeland T M, Nilssen R, Mo O 1994 Simulation of power electronic and motion control systems - An overview. Proc. IEEE Conf. 1: 1287-1302

Nagel L W 1975 SPICE2: A computer program to simulate semiconductor circuits. Memo. ERLM520, Univ. of Berkeley, CA

Meyer W S, Liu T H 1974 EMTP Rule Book. Bonneville Power Administration

Nilssen R, Mo O 1990 KREAN, a new simulation program for power electronics. IEEE Power Electron. Syst. Conf. Rec. 90 pp 506-511

Nilssen R 1991 Programmable module in simulation programs for power electronic circuits. EPE-91, Firence, Italy, 4: 373-377

Oms F et al 1989 SCRIPT simulator from converter to semiconductor. EPE' 89 Aachen, vol 1, pp 207-212

Rajagopalan V 1988 Computer-aided analysis of power electronic systems. IECON'88, Singapore, Invited Paper, 88CH2602-1, pp 528-533 
Rajagopalan V 1987 Computer-aided analysis of power electronic systems. (New York: Marcel Dekker)

Rajagopalan V 1995 Modeling and simulation of power electronic converters for power supplies. IEEE Conf. Rec. IECON 95 Invited Paper, pp 27-32

Rajagopalan V, Sankara Rao K 1975 ATOSEC Users' Manual, Département de génie électrique, Université du Québec à Trois-Rivières, Canada

Rajagopalan V et al 1990 User friendly dedicated power electronic converter simulator. IEEE Workshop on Computers in Power Electronics, pp 183-204

Rajagopalan V, Debebe K, Chandrasekaran A, Sudha S A 1992 User-friendly dedicated power electronic converter simulator. IEEE Trans. Ind. Electron. 39: 55-62

Rajagopalan V, Yao Z, Brillon D, Doumbia M L 1995 CATPELS: Computer-Aided Tutor for Power Electronic Systems. Université du Québec à Trois-Rivières, Trois-Rivières, (Québec), G9A 5H7, Canada

Simmon 1993 Simnon for Windows. SSPA Systems, Sweden

Simulink 1992 SIMULINK User Guide. The Math Works

Sudha S A, Chandrasekaran A, Rajagopalan V 1993 New approach to switch modeling in the analysis of power electronic systems. Inst. Elec. Eng. Proc. B140: 115-123

Tymerski R 1993 A fast time-domain simulator for power electronic systems. IEEE APEC-93, pp 477-483

Verghese G C, Elbuluk M C, Kassakian J G 1986 A general approach to sample-data modeling for power electronic circuits. IEEE Trans. Power Electron. 1: 76-89

Xu C 1990 Modeling and simulation of power electronics using SABER. Presented at First European Meeting of SABER User's Group, Newbury, England

Yao Z, Dawande M, Rajagopalan V 1997 Controller design for advanced reactive power compensators based on input-output linearization. Acceptance received for IEEE Power Electron. Syst. Conf. 97 pp 936-941 